\title{
BIO-ANALYTICAL METHOD DEVELOPMENT AND VALIDATION OF AVELUMAB, AXITINIB AND ITS APPLICATION TO PHARMACOKINETIC STUDIES IN RABBIT PLASMA BY USING LCMS/MS
}

\author{
SYED RAFI ${ }^{*}$, KANTIPUDI RAMBABU ${ }^{1}$ \\ $1^{*}$ Department of Chemistry, RVR and JC College of Engineering, Chowdavaram, Guntur, Andhra Pradesh, India \\ Email: rafiresearch2@gmail.com
}

Received: 14 Jun 2021, Revised and Accepted: 28 Jul 2021

\begin{abstract}
Objective: An easy, quick, precise, active and reproducible LC-MS/MS technique was developed for the bioanalytical method of Avelumab and Axitinib using Cytarabine as an internal standard.

Methods: This article summarizes the recent progress on bioanalytical LC-MS/MS methods using waters x-bridge phenyl column (150x4.6 mm, $3.5 \mu$ ) column and organic mobile phase of 0.1\% Tri fluoro acetic acid and Acetonitrile in 50:50 ratio.

Results: The calibration curve was linear in the range of 2-40 ng/ml for avelumab and 0.5-10 ng/ml axitnib. Accuracy, precision, recovery, matrix effect and stability results were found to be within the suitable limits. Simple and efficient method was developed and utilized in pharmacokinetic studies to see the investigated analyte in body fluids.
\end{abstract}

Conclusion: The application denotes all the parameters of system suitability, specificity, linearity and accuracy are in good agreement with USFDA guidelines and applied effectively for the investigation of pharmacokinetic studies in rabbit.

Keywords: Avelumab, Axitinib, LC-MS/MS, USFDA guidelines, Rabbit plasma

(C) 2021 The Authors. Published by Innovare Academic Sciences Pvt Ltd. This is an open-access article under the CC BY license (https://creativecommons.org/licenses/by/4.0/] DOI: https://dx.doi.org/10.22159/ijap.2021v13i5.42415. Journal homepage: https://innovareacademics.in/journals/index.php/ijap

\section{INTRODUCTION}

Avelumab is a fully human monoclonal antibody medication for the treatment of merkel cell carcinoma, urothelial carcinoma, and renal cell carcinoma [1]. In adults and children at least $12 \mathrm{y}$ of age, treatment of a particular form of skin cancer, metastatic merkel cell carcinoma (MCC) [2]. Up to $12 \%$ of patients with MCC have incorrectly prognosed distant metastatic disease (mMcc). And progression to mmolcc is fruequentin up to 21 percent in patients with local or regional disease [3]. Although no prospective clinical chemotherapy [4] have been performed and no regime has been officially approved for mmolCC treatment, combinations of platinum/etoposide have been commonly used and reasonably high objective response rates (ORRs) have been achieved, response time, however, is limited and no significant survival benefit has been reported. Highlighting the need for alternative treatments. Recently, clinical trials with immune checkpoint inhibitors targeting the programmed death-ligand 1(PD-L1)/programmed death 1(PD-1) interaction have shown clinical activity and durable responses in patients with advanced MCC [5]. Avelumab is given by an infusion into the vein through a special filter over 60 min every two weeks. Avelumab gives side effects to a few patients after discontinuation, such as immune-related side effects and other common side effects, such as feeling tired, muscle pain, muscles, joints, tendons, ligaments, nerves, and increased liver enzymes [6-10].

Axitinib is a small molecule Tyrosine kinase inhibitor [11] developed by Pfizer under the trade name Inlyta which take orally. It has been shown to significantly inhibit the growth of breast cancer in animal models [12]. And has shown partial response in clinical trials with Renal cell carcinoma (RCC) and several other tumour types [13]. It was approved for RCC by the U. S. Food and drug Administration after showing a modest increase in Progression-free survival. There have been reports of fatal adverse effects. Most common effects are Diarrhea, High blood pressure [14], Fatigue, Loss of appetite, Anemia [15].

In drug discovery and production, bioanalysis is an integral component. Bioanalysis is related to the analysis of analytes in biological samples (drugs, metabolites, biomarkers) and requires several phases from sample collection to analysis of samples and reporting of results. The first phase is the selection of samples from clinical or preclinical trials, then sending the samples for analysis to the laboratory. Sample clean-up is the second step and it is a very critical step in bioanalysis. A robust and stable sample preparation system should be implemented in order to reach accurate results. The task of sample preparation is to remove interference from the matrix of the sample and improve the efficiency of the analytical method. Preparation of samples is often labour intensive and time-consuming The last step is the examination and detection of samples. The method of choice in bioanalytical laboratories is liquid chromatographytandem mass spectrometry (LC-MS/MS) for separation and detection. This is attributed to the high selectivity and high sensitivity of the LCMS/MS technique. In addition, the information about the analyte chemical structure and chemical properties is important to be known before the start of bioanalytical work. This review provides an overview of bioanalytical method development and validation. The main principles of method validation will be discussed. Commonly used sample preparation techniques will be presented. In addition, the role of LC-MS/MS in modern bioanalysis will be discussed. In the present review, we have our focus on the bioanalysis of small molecules. Till date, no method is available for bioanalysis of eliglustat in any type of biological matrix. This is the first time to report a bioanalytical method for these drugs.

\section{MATERIALS AND METHODS}

\section{Chemicals and reagents}

Acetonitrile and Tri fluoro acetic acid-water (HPLC grade) were purchased from Merck (India) Ltd, Wroli, Mumbai, India. All APIs of Avelumab and Axitinib as reference standards were procured from spectrum pharma research solutions pvt ltd, Hyderabad.

\section{Equipment}

An HPLC system (waters alliance e2695 model) connected with mass spectrometer QTRAP 5500 triple quadrupole instrument (sciex) was used. By the Empower 2.0 software operation was performed [16-18]

\section{Pharmacokinetic study}

\section{Selection of animals}

In vivo pharmacokinetic studies, 6 healthy white New Zealand rabbits $(2.0-2.5 \mathrm{~kg})$ were obtained from Biological E Limited, 
Hyderabad, India. The protocol of the animal study was approved by institute of animal ethics committee (Reg. No: 1074/PO/ Re/S/05/CPCSEA).

\section{Chromatographic conditions}

Chromatographic separation, using x-bridge phenyl $(150 \times 4.6 \mathrm{~mm}$, 3.5 micron) columns, was administered in isocratic mode at room temperature. As a mobile phase, a mix of 0.1 percent trifluoroacetic acid and acetonitrile at $50: 50 \mathrm{v} / \mathrm{v}$ with a flow of $1.0 \mathrm{ml} / \mathrm{min}$ was used. $10 \mu \mathrm{l}$ was the injection rate and the run time was $8 \mathrm{~min}$.

\section{Preparation of standard and internal control samples}

\section{Preparation of standard stock solution}

Take $20 \mathrm{mg}$ of the Avelumab and $5 \mathrm{mg}$ of Axitinib working standards is taken into a $100 \mathrm{ml}$ volumetric flask and $70 \mathrm{ml}$ of diluents and sonicate for $10 \mathrm{~min}$ to dissolve the contents completely and makeup to the mark with diluent. Further dilution by taking $0.1 \mathrm{ml}$ into $100 \mathrm{ml}$ volumetric flask. From the above solution $4 \mathrm{ml}$ of the solution is taken into the $10 \mathrm{ml}$ volumetric flask and makeup to the mark with the diluent.

\section{Preparation of internal standard}

Take $50 \mathrm{mg}$ internal standard of Cytarabine into a $100 \mathrm{ml}$ volumetric flask and makeup to the mark with diluent and sonicate for ten minutes to dissolve the contents completely. From this solution, take $0.2 \mathrm{ml}$ of the solution into $50 \mathrm{ml}$ volumetric flask. From the above solution $1 \mathrm{ml}$ is taken into the $10 \mathrm{ml}$ volumetric flask and makeup to the mark with the diluent.

\section{Preparation of standard solution}

For standard preparation, $200 \mu \mathrm{l}$ of plasma was taken and $300 \mu \mathrm{l}$ of ACN into a $2 \mathrm{ml}$ centrifuge tube and $500 \mu \mathrm{l}$ of standard stock solutions and $500 \mu \mathrm{l}$ of IS and $500 \mu \mathrm{l}$ of diluents were added and vortexed for $10 \mathrm{~min}$. These samples were further subjected for centrifuge at $5000 \mathrm{rpm}$ for $30 \mathrm{~min}$. Collect the solution and filter through $0.45 \mu$ nylon syringe filter and the clear solution was transferred into vial and injected into a system.

\section{Bioanalytical Method validation}

The method was validated [19-27] in selective, sensitive, linearity, accuracy and precise, matrix condition, recovery study, re-injection reproducibility and stability.

\section{Selectivity}

By analyzing the six different rabbit's plasma samples and to check interference at the retention time, selectivity was conducted.

\section{Matrix effect}

By comparing the height area ratio from the six various drug free plasma samples for avelumab and axitinib to get matrix effect. Experiments were performed at MQC levels in triplicate with six different plasma lots with a suitable precision of $\leq 15 \%$.

\section{Precision and accuracy}

It was determined by replicate analysis of internal control samples at a lower limit of quantification (LLOQ), low-quality control (LQC), medium quality control (MQC), top quality control (HQC) levels. The half of CV should be less than $15 \%$ and accuracy should be within $15 \%$ except LLOQ where $20 \%$.

\section{Recovery}

The analysis of six samples reproduce at each internal control concentration is by extracting the avelumab and axitinib. By comparing the height areas of extracted standards to the height areas of unextracted standards, recovery is evaluated.

\section{Carryover}

Carryover [28, 29] deals with the analyte retained by the chromatographic system during the matrix with an analyte concentration ULOQC and above the diluting this sample with blank matrix.

\section{Dilution integrity}

By spiking the matrix with an analyte concentration above the ULOQC and diluting this sample with a blank matrix, the dilution integrity should be explained.

\section{Stability}

By comparing the act of stock solution stability [30] under the stability sample with the sample from the fresh stock sample preparation. Sample Stability studies in plasma were performed at the LQC and HQC concentration levels using six replicates at each level. Analyte was considered stable if the change is smaller amount than $15 \%$ as per US FDA guidelines. The perfectness of spiked rabbit plasma stored at room temperature was evaluated for twenty-four hrs. The stability of spiked rabbit plasma stored at RT in autosampler was evaluated for $24 \mathrm{~h}$. The autosampler stability (LQC, MQC and HQC) was evaluated by comparing the extract plasma samples that were injected immediately with the samples that were re-injected after storing with wet extract stability at room temperature after $12 \mathrm{~h}$ and $18 \mathrm{~h}$ at $2-8{ }^{\circ} \mathrm{C}$. The reinjection reproducibility was evaluated by comparing the extracted plasma samples that were injected immediately with the samples that were re-injected after storing in the dry extract stability at room temperature after $12 \mathrm{~h}$ and $18 \mathrm{~h}$ at $-20^{\circ} \pm 3{ }^{\circ} \mathrm{C}$. The freeze-thaw stability was conducted by comparing the steadiness samples that had been frozen at- $31{ }^{\circ} \mathrm{C}$ and thawed 3 times with freshly spiked internal control samples. The short-term stability was conducted $7 \mathrm{~d}$ at $7{ }^{\circ} \mathrm{C}$. For long-term stability evaluation, the concentrations obtained after $24 \mathrm{~h}$ were compared with the initial concentration.

\section{Pharmacokinetic study}

Before experimentation, all animals are starved overnight and had water ad-libitum. Topical anesthetic procedure was used. Pharmacokinetic evaluation was performed for avelumab and axitinib formulations. The samples were administered to each rabbit under fasting conditions. After oral administration of avelumab and axetinib, blood samples were collected from rabbit marginal ear vein using a 25-guage, 5/8 inch needle by clipping the marginal ear vein with a paper clip shown in fig. 1 with the volume of $0.5 \mathrm{ml}$ to $1.0 \mathrm{ml}$ at $0.5,2,4,8,12,16,20,24,28,32$ and $36 \mathrm{~h}$. The blood was collected in Eppendorf containing 10\% EDTA solution. Blood was centrifuged at $5000 \mathrm{rpm}$ for $30 \mathrm{~min}$ at $2-8{ }^{\circ} \mathrm{C}$ temperature. The clear supernatant plasma were collected and stored at- $30^{\circ} \mathrm{C}$ till its analysis. The plasma samples were treated for liquid-liquid phase extraction and analyzed for drug content with a developed analytical method. After the study, the animals were returned to the animal house for rehabilitation.

The pharmacokinetic parameters for avelumab and axetinib oral administration were determined from plasma concentration data. Pharmacokinetic parameters like AUC, Cmax, Tmax the time at which Cmax occurred, Kel, $\mathrm{t}^{1} \frac{2}{2}$, Ka and MRT were calculated using the data. Data was measured by the trapezoidal rule method from time zero to infinity of the concentration-time curve. Cmax and Tmax were obtained from the graph. All values are expressed in mean \pm SD.

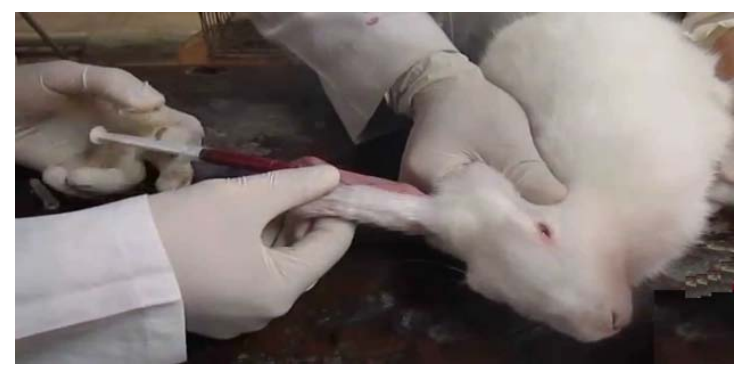

Fig. 1: Sampling of rabbit

\section{RESULTS AND DISCUSSION}

The maximum response on air pressure chemical ionization mode selected in this method is by having the electrospray ionization. The 
mobile phase flow of $10 \mu \mathrm{l} / \mathrm{min}$ avelumab and axitinib are highly responsive in the positive ion mode to offer sensitivity and signal stability with the continuous flow to the electrospray ion.

\section{Specificity}

The specificity of the method to research Avelumab and Axitinib simultaneously is proved. The chromatograms of blank and standard as shown in fig. 2, 3. The chromatograms of blank rabbit plasma and standard having no interference peaks were observed.

\section{Matrix effect}

Percent RSD for within the signal, ion suppression/enhancement was observed as 1.0 percent for Avelumab and Axitinib in LCMS/MS, suggesting that under these circumstances, the matrix effect [31] on analyte ionization is within an acceptable range of ionization. In matrix effect, LQC and HQC of Avelumab were 99.6 and 99.9 and axitinib were $99.4,99.8 \%$. \% CV of both drugs at LQC level were $1.31,1.28$ and $\mathrm{HQC}$ level is $0.28,1.61$ respectively. It indicates that the matrix effect on the ionization of the analyte is within the suitable limit.

\section{Linearity}

The peak area ratio of calibration standards was proportional to the concentration. The concentration range of Avelumab is $2-40 \mathrm{ng} / \mathrm{ml}$ and Axitinib is $0.5-10 \mathrm{ng} / \mathrm{ml}$. Linearity results of Avelumab and Axitinib were shown in following table 1 and their calibration plots were shown in fig. 4 [32]. The calibration curves were appeared linear and the coefficient of correlation was found to be 0.999 for Avelumab and Axitinib.

\section{Precision and accuracy}

By pooling all individual assay results of different internal control samples, the accuracy and precision were calculated. It was obvious, based on the data provided, that the strategy was precise and effective. The precision results of avelumab and axitinib were shown in table 2, 3. avelumab accuracy results in quality control samples 98.8-99.9 and axitinib accuracy results in quality control samples 99.4-99.8. Half of Avelumab and Axitinib CV is $<5 \%$ of total internal control samples.

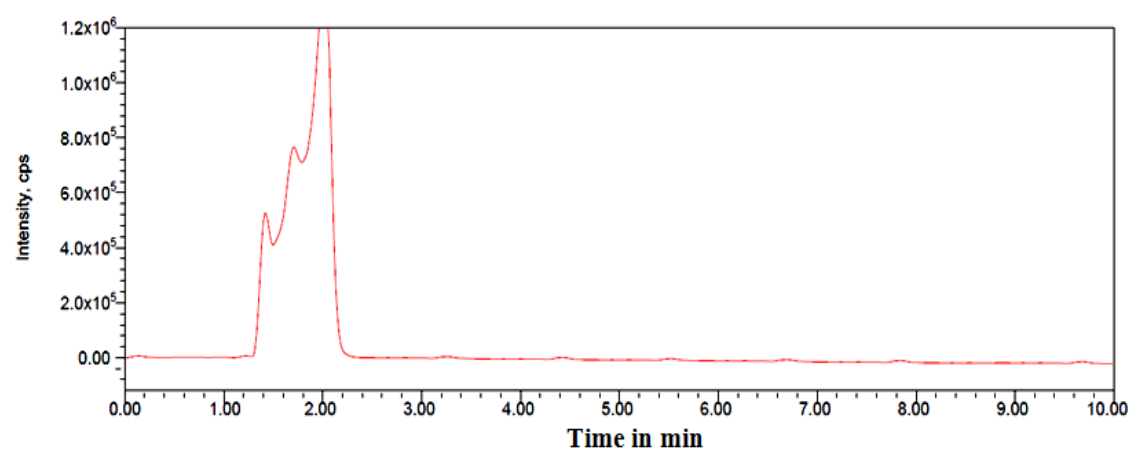

Fig. 2: Chromatogram of blank

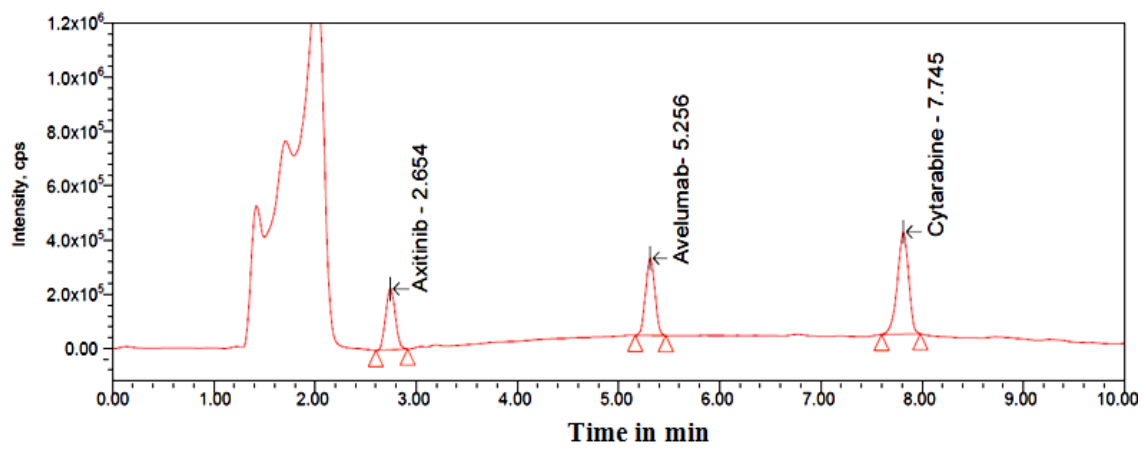

Fig. 3: Chromatogram of standard

Table 1: Results of linearity

\begin{tabular}{lllll}
\hline Linearity & Avelumab & & Axitinib & Area response ratio \\
\cline { 2 - 5 } & Conc. $(\mathbf{n g} / \mathbf{m l})$ & Area response ratio & Conc. $(\mathbf{n g} / \mathbf{m l})$ & 0.054 \\
\hline 1 & 2 & 0.102 & 0.5 & 0.119 \\
2 & 5 & 0.221 & 1.25 & 0.240 \\
3 & 10 & 0.432 & 2.5 & 0.362 \\
4 & 15 & 0.653 & 3.75 & 0.513 \\
5 & 20 & 0.855 & 5 & 0.613 \\
6 & 25 & 1.059 & 6.25 & 0.733 \\
7 & 30 & 1.278 & 7.5 & 0.996 \\
8 & 40 & 1.737 & 10 & 0.0970 \\
Slope & & 0.0420 & Slope & 0.00395 \\
Intercept & & 0.01672 & Intercept & 0.99915 \\
CC & & 0.99958 & CC & \\
\hline
\end{tabular}




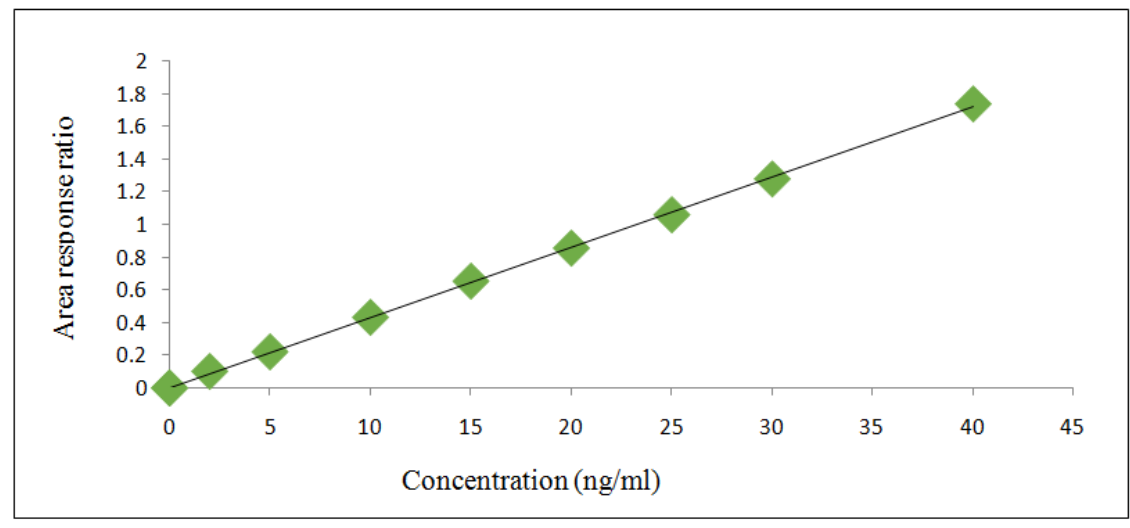

A

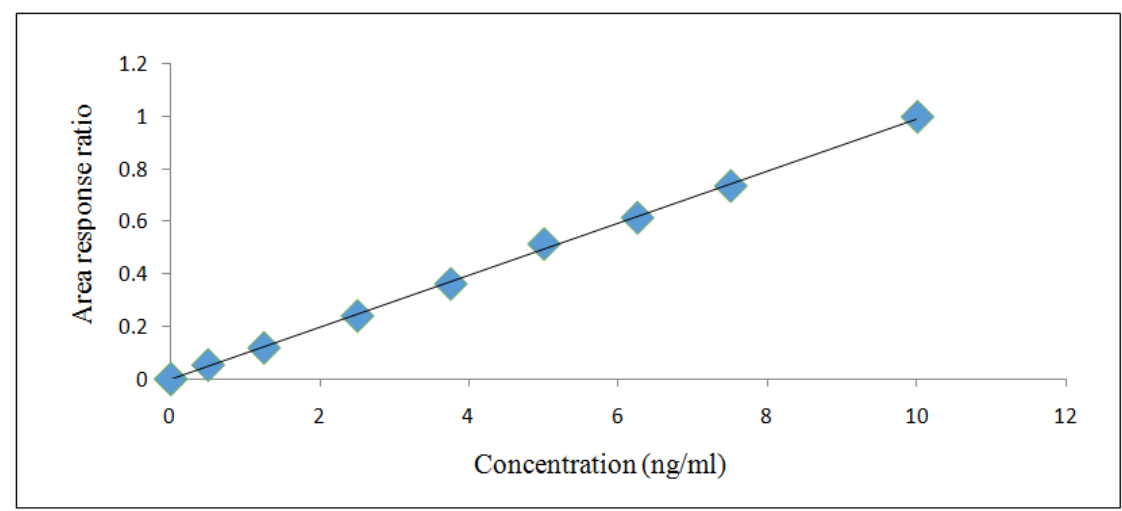

Fig. 4: Calibration plots of (A) Avelumab and (B) Axitinib

Table 2: Precision and accuracy of avelumab

\begin{tabular}{llll}
\hline QC name & LLQC & LQC & MQC \\
\hline Conc.(ng/ml) & $2 \mathrm{ng} / \mathrm{ml}$ & $10 \mathrm{ng} / \mathrm{ml}$ & $20 \mathrm{ng} / \mathrm{ml}$ \\
QC sample-1 & 2.182 & 10.194 & 20.165 \\
QC sample-2 & 2.314 & 10.652 & 20.125 \\
QC sample-3 & 2.568 & 10.353 & 20.145 \\
QC sample-4 & 2.478 & 10.485 & 30.138 \\
QC sample-5 & 2.121 & 10.865 & 30.125 \\
QC sample-6 & 2.957 & 10.586 & 30.242 \\
Mean & 2.4133 & 10.506 & 20.569 \\
SD & 0.302 & 0.262 & 20.685 \\
\%CV & 1.124 & 0.965 & 30.356 \\
Accuracy & 99 & 99.624 & 30.5613 \\
\hline
\end{tabular}

Mean+SD $(n=6)$

Table 3: Precision and accuracy of axitinib

\begin{tabular}{|c|c|c|c|c|}
\hline Qc name & LLQC & LQC & MQC & HQC \\
\hline Conc.(ng/ml) & 0.5 & 2.5 & 5 & 7.5 \\
\hline QC sample-1 & 0.512 & 2.528 & 5.1 & 7.526 \\
\hline QC sample-2 & 0.534 & 2.678 & 5.248 & 7.589 \\
\hline QC sample-3 & 0.538 & 2.798 & 5.384 & 7.682 \\
\hline QC sample-4 & 0.548 & 2.854 & 5.468 & 7.763 \\
\hline QC sample-5 & 0.553 & 2.93 & 5.528 & 7.542 \\
\hline QC sample-6 & 0.567 & 2.961 & 5.687 & 7.524 \\
\hline Mean & 0.542 & 2.791 & 5.402 & 7.604 \\
\hline Stddev & 0.0171 & 0.149 & 0.190 & 0.089 \\
\hline$\% \mathrm{CV}$ & 1.895 & 0.985 & 0.885 & 0.985 \\
\hline Accuracy \% & 99.145 & 98.354 & 99.568 & 100.128 \\
\hline
\end{tabular}

Mean+SD $(n=6)$ 


\section{Recovery}

The recoveries for Avelumab and Axitinib at LQC, MQC and HQC levels the results demonstrated that the bioanalytical method had good extraction efficiency. This also showed that the recovery wasn't hooked into concentration. The recoveries for Avelumab (98.81\% $100.62 \%$ ) and Axitinib (99.41\%-100.18\%) at LQC, MQC and HQC levels and \% CV ranged from 0.21-0.72 for Avelumab and 0.84-1.83 for Axitinib. The results demonstrated that the bioanalytical method had good extraction efficiency.

\section{Ruggedness}

The percent recoveries and percent CV of Avelumab and Axitinib determined with two different analysts and on two different columns were within acceptable criteria in HQC, LQC, MQC and LLQC samples. The results proved method is ruggedness. The percent recoveries ranged from 99.61-100.73\% for Avelumab and $99.24 \%-99.91 \%$ for Axitinib. The \%CV values ranged from 0.09-0.31for Avelumab and 0.61-1.11 for Axitinib. The results proved method is ruggedness.

\section{Autosampler carryover}

Peak area response of Avelumab and Axitinib, wasn't observed within the blank rabbit plasma samples after successive injections of LLQC and ULQC at the retention times of Avelumab and Axitinib. In autosampler carryover this method doesn't exhibit autosampler carryover.

\section{Stability}

Avelumab and Axitinib solutions were prepared with diluents for solution stability analysis and placed in a refrigerator at 2$8{ }^{\circ} \mathrm{C}$. Fresh stock solutions were associated with stock solutions that were prepared $24 \mathrm{~h}$ earlier. The plasma stability of the benchtop and autosampler was stable for twenty-four hours, and $24 \mathrm{~h}$ at $20{ }^{\circ} \mathrm{C}$ in the autosampler. It became apparent from future stability that Avelumab and Axitinib were stable at a storage temperature of $-30{ }^{\circ} \mathrm{C}$ for up to $24 \mathrm{~h}$. The overall stability results of avelumab and axitiniib have been stated in the below table 4,5 .

Table 4: Stability results of avelumab

\begin{tabular}{|c|c|c|c|c|}
\hline \multicolumn{2}{|c|}{ Stability experiment spiked plasma } & \multirow{2}{*}{$\begin{array}{l}\text { Spiked plasma conc. }(\mathrm{n}=6, \mathrm{ng} / \mathrm{ml}) \\
10\end{array}$} & \multirow{2}{*}{$\begin{array}{l}\text { Conc. Measured }(\mathrm{n}=6, \mathrm{ng} / \mathrm{ml}) \\
10.135\end{array}$} & \multirow{2}{*}{$\frac{\text { \%CV }}{1.246}$} \\
\hline Bench top stability & LQC & & & \\
\hline & MQC & 20 & 20.257 & 0.858 \\
\hline & HQC & 30 & 30.458 & 0.968 \\
\hline \multirow[t]{3}{*}{ Auto sampler stability } & LQC & 10 & 10.897 & 0.952 \\
\hline & MQC & 20 & 20.589 & 0.856 \\
\hline & HQC & 30 & 30.124 & 0.977 \\
\hline \multirow[t]{3}{*}{ Long term(Day28) stability } & LQC & 10 & 10.368 & 0.985 \\
\hline & MQC & 20 & 20.354 & 0.856 \\
\hline & HQC & 30 & 30.126 & 0.746 \\
\hline \multirow[t]{3}{*}{ Wet extract stability } & LQC & 10 & 10.328 & 0.789 \\
\hline & MQC & 20 & 20.856 & 0.852 \\
\hline & HQC & 30 & 30.175 & 0.845 \\
\hline \multirow[t]{3}{*}{ Dry extract stability } & LQC & 10 & 10.689 & 0.963 \\
\hline & MQC & 20 & 20.657 & 0.784 \\
\hline & HQC & 30 & 30.821 & 0.894 \\
\hline \multirow[t]{3}{*}{ Freeze thaw stability } & LQC & 10 & 10.628 & 0.854 \\
\hline & MQC & 20 & 20.145 & 0.874 \\
\hline & HQC & 30 & 30.286 & 0.745 \\
\hline \multirow[t]{3}{*}{ Short term stability } & LQC & 10 & 10.369 & 0.841 \\
\hline & MQC & 20 & 20.486 & 1.456 \\
\hline & HQC & 30 & 30.289 & 1.025 \\
\hline
\end{tabular}

mean $\pm S D(n=6)$

Table 5: Stability results of axitinib

\begin{tabular}{|c|c|c|c|c|}
\hline \multicolumn{2}{|c|}{ Stability experiment spiked plasma } & \multirow{2}{*}{$\frac{\text { Spiked plasma conc. }(\mathrm{n}=\mathbf{6}, \mathrm{ng} / \mathrm{ml})}{2.5}$} & \multirow{2}{*}{$\begin{array}{l}\text { Conc. Measured (n=6,ng/ml) } \\
2.534\end{array}$} & \multirow{2}{*}{$\frac{\% \mathrm{CV}}{1.042}$} \\
\hline Bench top stability & LQC & & & \\
\hline & MQC & 5 & 5.12 & 0.986 \\
\hline & HQC & 7.5 & 7.548 & 0.974 \\
\hline \multirow[t]{3}{*}{ Auto sampler stability } & LQC & 2.5 & 2.525 & 0.981 \\
\hline & MQC & 5 & 5.321 & 0.874 \\
\hline & $\mathrm{HQC}$ & 7.5 & 7.584 & 0.954 \\
\hline Long term & LQC & 2.5 & 2.587 & 0.845 \\
\hline \multirow[t]{2}{*}{ (Day 28)stability } & MQC & 5 & 5.874 & 0.768 \\
\hline & HQC & 7.5 & 7.582 & 0.734 \\
\hline \multirow[t]{3}{*}{ Wet extract stability } & LQC & 2.5 & 2.574 & 0.861 \\
\hline & MQC & 5 & 5.369 & 0.827 \\
\hline & $\mathrm{HQC}$ & 7.5 & 7.514 & 0.965 \\
\hline \multirow[t]{3}{*}{ Dry extract stability } & LQC & 2.5 & 2.542 & 1.142 \\
\hline & MQC & 5 & 5.841 & 1.254 \\
\hline & $\mathrm{HQC}$ & 7.5 & 7.586 & 0.964 \\
\hline \multirow[t]{3}{*}{ Freeze thaw stability } & LQC & 2.5 & 2.564 & 0.985 \\
\hline & MQC & 5 & 5.684 & 1.246 \\
\hline & $\mathrm{HQC}$ & 7.5 & 7.521 & 1.103 \\
\hline \multirow[t]{3}{*}{ Short term stability } & LQC & 2.5 & 2.574 & 0.824 \\
\hline & MQC & 5 & 5.231 & 0.987 \\
\hline & HQC & 7.5 & 7.541 & 1.485 \\
\hline
\end{tabular}

mean $\pm \operatorname{SD}(n=6)$ 


\section{In vivo pharmacokinetic evaluation}

The plasma concentration-time profiles of avelumab and axitinib in rabbit are shown in fig. 5 . The graph indicated a bell-shaped curve in both cases of the experimental formulation. Avelumab and axitinib could be traced to be present in the blood for $24 \mathrm{~h}$ and $4 \mathrm{~h}$ after oral administration, which indicates the effectiveness of drug release from the formulation.

The pharmacokinetic parameters Cmax, Tmax, T1/2, Kel, Ka, AUC0-t AUC0- $\infty$, AUMC 0-24, AUMCt- $\infty$, MRT0-24, MRT0- $\infty$ were calculated and the data is shown in table 6 . The Cmax for avelumab and axitiniib were found to be $16.9 \mathrm{ng} / \mathrm{ml}$ and $4.9 \mathrm{ng} / \mathrm{ml}$, respectively. The Tmax for avelumab and axitiniib were found to be $24 \mathrm{~h}$ and $4 \mathrm{~h}$, respectively. The $t^{1} \frac{1}{2}$ values were $32 \mathrm{~h}$ and $24 \mathrm{~h}$ respectively for avelumab and axitiniib. The Kel for avelumab and axitiniib 0.41 and $0.005 \mathrm{~h}-1$. The Ka values of avelumab and axitiniib were found to be 0.13 and $1.41 \mathrm{~h}-1$, respectively. The AUC0-t for avelumab and axitiniib were found to be 273 and $63 \mathrm{ng}-\mathrm{h} / \mathrm{ml}$, respectively. The

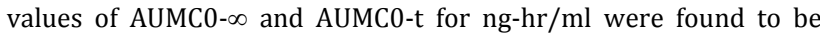
$352.18,141.11 \mu \mathrm{g} \mathrm{h} \mathrm{ml-1}$ and 273.06, 63.18 $\mu \mathrm{g} \mathrm{h} \mathrm{ml-1.} \mathrm{The} \mathrm{MRT0-24}$ and MRT0- $\infty$ for $\mathrm{ng}-\mathrm{hr} / \mathrm{ml}$ were found to be $24.17,6.31$ and 36.0 , 36.0 respectively, shown in table 6.

Table 6: Pharmacokinetic parameters of avelumab and axitinib

\begin{tabular}{|c|c|c|}
\hline Pharmacokinetic parameters & Avelumab & Axitinib \\
\hline $\mathrm{AUC}_{0-\mathrm{t}}$ & $273 \mathrm{ng}-\mathrm{h} / \mathrm{ml}$ & $63 \mathrm{ng}-\mathrm{h} / \mathrm{ml}$ \\
\hline $\mathrm{C}_{\max }$ & $16.9 \mathrm{ng} / \mathrm{ml}$ & $4.9 \mathrm{ng} / \mathrm{ml}$ \\
\hline $\mathrm{AUC}_{0-\infty}$ & $352 \mathrm{ng}-\mathrm{h} / \mathrm{ml}$ & $141 \mathrm{ng}-\mathrm{h} / \mathrm{ml}$ \\
\hline$t_{\max }$ & $24 \mathrm{~h}$ & $4 \mathrm{~h}$ \\
\hline $\mathrm{T}_{1 / 2}$ & $32 \mathrm{~h}$ & $24 \mathrm{~h}$ \\
\hline $\mathrm{k}_{\mathrm{el}}$ & $0.41 \mathrm{~h}-1$ & $0.005 \mathrm{~h}-1$ \\
\hline $\mathrm{Ka}$ & $0.13 \mathrm{~h}-1$ & $1.41 \mathrm{~h}-1$ \\
\hline MRT0-24 & $24.17 \mathrm{ng}-\mathrm{h} / \mathrm{ml}$ & $6.31 \mathrm{ng}-\mathrm{h} / \mathrm{ml}$ \\
\hline MRT0- $\infty$ & $36.0 \mathrm{ng}-\mathrm{h} / \mathrm{ml}$ & $36.0 \mathrm{ng}-\mathrm{h} / \mathrm{ml}$ \\
\hline
\end{tabular}

$\mathrm{AUC}_{0-\infty}$ : Area under the curve extrapolated to infinity, $\mathrm{AUC}_{0-\text { - }}$ : Area under the curve up to the last sampling time, $\mathrm{C}_{\mathrm{max}}$ The maximum plasma concentration, $\mathrm{T}_{\max }$ : The time to reach peak concentration, $\mathrm{T}_{1 / 2}$ : Time the drug concentration, Kel: Elimination rate constant, Ka: Absorption rate constant, MRT: Mean residence time.

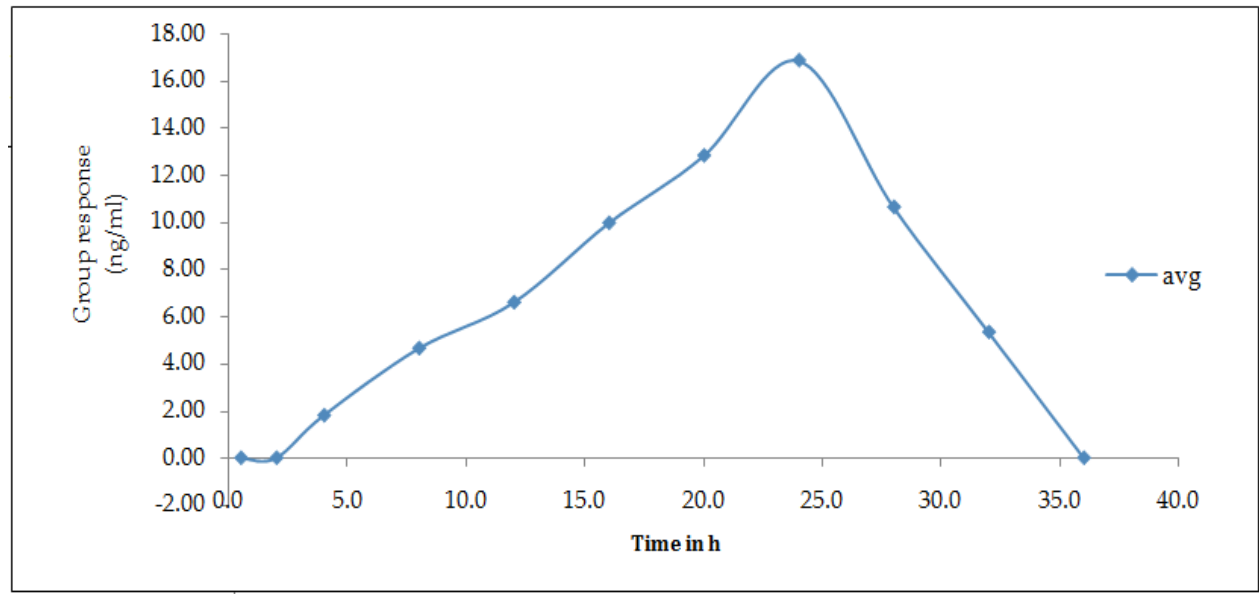

A

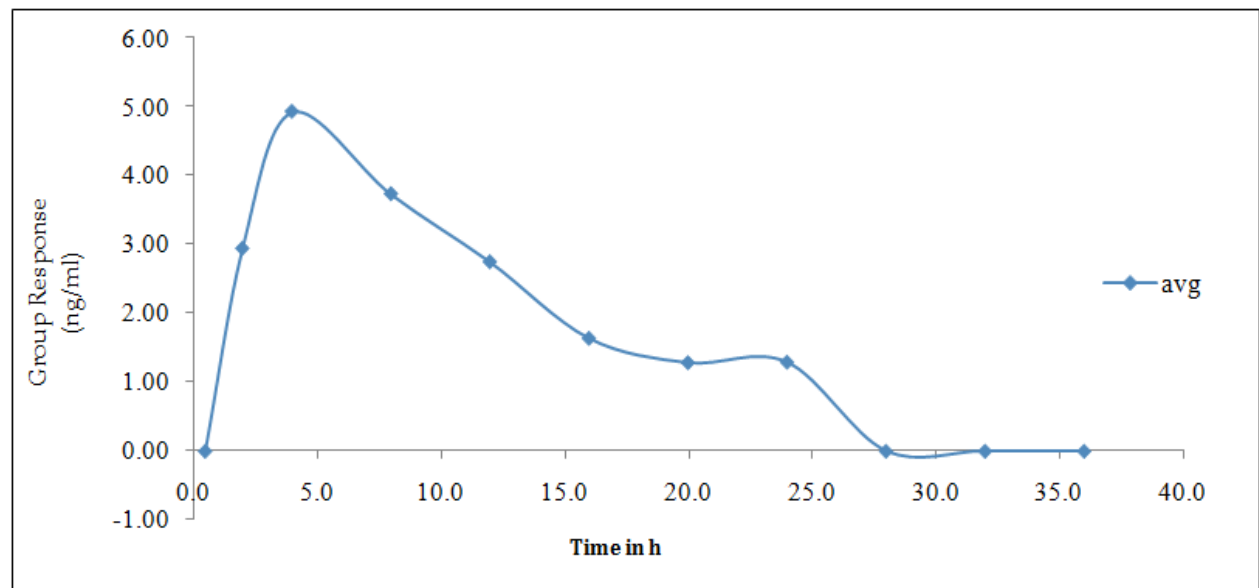

Fig. 5: Recovery plot (A) Avelumab and (B) Axitinib 


\section{CONCLUSION}

For the primary time higher sensitive HPLC-ESI-LCMS/MS method was developed and validated for the determination of Avelumab and Axitinib in rabbit plasma. Here the described method is rugged, fast, reproducible bioanalytical method. This method was validated according to USFDA guidelines. Simple and efficient method was developed and may be utilized in pharmacokinetic studies and to see the investigated analyte in body fluids.

\section{ACKNOWLEDGEMENT}

I thankful to my guide for encouragement and supporting to finish this research work.

\section{FUNDING}

Nil

\section{AUTHORS CONTRIBUTIONS}

All authors have contributed equally.

\section{CONFLICTS OF INTERESTS}

Author declares that there have been no conflicts of interest.

\section{REFERENCES}

1. Quinn DI, Lara PN. renal-cell cancer-targeting an immune checkpoint or multiple kinases. N Engl J Med 2015;373:1872-4.

2. Pulitzer, Melissa. Merkel cell carcinoma. Surgical Pathol Clin 2017;10:399-408.

3. C Lebbe, JC Becker, JJ Grob, J Malvehy, V Del Marmol, H Pehamberger, et al. Diagnosis and treatment of merkel cell carcinoma. European consensus-based interdisciplinary guideline. Eur J Cancer 2015;5:2396-403.

4. Beumer JH, Chu E, Salamone SJ. Body-surface area-based chemotherapy dosing: appropriate in the 21st century? J Clin Oncol 2012;30:3896-7.

5. D Schadendorf, C Lebbe, A ZurHausen, MF Avril, S Hariharan, M Bharmal, et al. Merkel cell carcinoma: epidemiology, prognosis, therapy and unmet medical needs. Eur J Cancer 2017;71:53-69.

6. PJ Allen, WB Bowne, DP Jaques, MF Brennan, K Busam, DG Coit. Merkel cell carcinoma: prognosis and treatment of patients from a single instituition. J Clin Oncol 2005;23:2300-9.

7. Johnston DE. Special considerations in interpreting liver function tests. Am Fam Physician 1999;59:2223-30.

8. P Nghiem, HL Kaufman, M Bharmal, L Mahnke, H Phatak, JC Becker. Systematic literature review of efficacy, safety and tolerability outcomes of chemotherapy regimens in patients with metastatic Merkel cell carcinoma. Future Oncol 2017;13:1263-79.

9. PT Nghiem, S Bhatia, EJ Lipson, RR Kudchadkar, NJ Miller, L Annamalai, et al. PD-1 blockade with pembrolizumab in advanced Merkel cell carcinoma. N Engl J Med 2016;374:2542-52.

10. Kwo, Paul Y, Cohen, Stanley M, Lim, Joseph K. acg clinical guideline: evaluation of abnormal liver chemistries. Am J Gastroenterol 2017;112:18-35.

11. Rivera Torres J, Jose ES. Src tyrosine kinase inhibitors: new perspectives on their immune, antiviral, and senotherapeutic potential. Front Pharmacol 2019;10:1011.

12. LJ Wilmes, MG Pallavicini, LM Fleming, J Gibbs, D Wang, KL Li, et al. AG-013736, a novel inhibitor of VEGF receptor tyrosine kinases, inhibits breast cancer growth and decreases vascular permeability as detected by dynamic contrast-enhanced magnetic resonance imaging. Magn Reson Imaging 2007;25:319-27.

13. B Rini, O Rixe, R Bukowski, MD Michaelson, G Wilding, G Hudes, et al. AG-013736, a multi-target tyrosine kinase receptor inhibitor, demonstrates anti-tumor activity in a phase 2 study of cytokine-refractory, metastatic renal cell cancer (RCC). J Clin Oncol 2005;23:4509.

14. Poulter NR, Prabhakaran D, Caulfield M. Hypertension. Lancet 2015;386:801-12.

15. Guagnozzi D, Lucendo AJ. Anemia in inflammatory bowel disease: a neglected issue with relevant effects. World J Gastroenterol (Review) 2014;20:3542-51.

16. Potturi Ramadevi, Kantipudi Rambabu. Bioanalytical method development and validation for ezetimibe and pitavastain and its applications to pharmacokinetic studies in rabbit plasma by using LCMS/MS. Int J Res Pharm Sci 2020;11:7854-62.

17. Asha Eluru, Surendra Babu K. Bioanalytical method development and validation for aplidine in rat plasma and their pharmacokinetic studies by LCMS. WJPPS 2019;8:1201-9.

18. D Ramchandran, Anita Kethipalli, Mannam Krishnamurthy. Bio analytical method development and validation of daunorubicin and cytrarabine in rat plasma by LC-MS/MS and its application in pharmacokinetic studies. J Pharm Sci Res 2020;12:381-6.

19. Mukta D Naykode, Durgacharan A Bhagwat, Swapnil D Jadhav, Harinath N. Analytical and bioanalytical method for quantification of pure azilsartan, not its salt by RP-HPLC. Res J Pharm Tech 2017;10:708-14.

20. Mayanka Singh, Manoj Charde, Rajesh Shukla, Rita MC. Determination of calcipotriene in calcipotriene cream $0.05 \%$ w/w by RP-HPLC method development and validation. Res J Pharm Tech 2011;4:1219-23.

21. Malathi S, Arunadevi N. Development and validation of stability-indicating simultaneous estimation of metformin and alogliptin in tablets by high-performance thin-layer chromatography. Int J Pharm Pharm Sci 2020;12:68-73.

22. Senthil Rajan D, Muruganathan G, Shivkumar K, Ganesh T. Development and validation of hplc method for simultaneous quantification of vasicine, glycyrrhizin and piperine in polyherbal cough syrup. Int J Curr Pharm Res 2020;12:15-9.

23. Palani Shanmugasundaram, Kamarapu SK. RP-HPLC method for the simultaneous estimation and validation of amlodipine besylate and atenolol in bulk and tablet dosage form in biorelevant dissolution medium (Fassif). Res J Pharm Tech 2017;10:3379-85.

24. Gomathy S, Narenderan ST, Meyyanathan SN, Gowramma B. Development and validation of hplc method for the simultaneous estimation of apigenin and luteolin in commercial formulation. J Crit Rev 2020;7:4785-90.

25. Ashutosh Kumar S, Manidipa Debnath, Seshagiri Rao JVLN, Gowri Sankar D. Development and validation of a sensitive RPHPLC method for simultaneous estimation of rosuvastatin and fenofibrate in tablet dosage form by using PDA detector in Gradient mode. Res J Pharm Tech 2016;9:549-54.

26. Malak Y, Al-Bathish AA, Gazy MK El-Jamal. Rp-hplc and chemometric methods for the determination of two antidiabetic mixtures; metformin hydrochloride-canagliflozin and metformin hydrochloride-gliclazide in their pharmaceutical formulation. Int J Pharm Pharm Sci 2020;12:83-94.

27. Gadhvi MP, Bhandari A, Suhagia BN, Desai UH. Development and validation of RP-HPLC method for simultaneous estimation of atazanavir and ritonavir in their combined tablet dosage form. Res J Pharm Tech 2013;6:200-3.

28. Koya Prabhakara Rao, Namburi LA Amara Babu, Kalyani Koganti, Babji Palakeeti, Koduri SV Srinivas. Related substances method development and validation of an LC-MS/MS method for the quantification of selexipag and its related impurities in rat plasma and its application to pharmacokinetic studies. SN Appl Sci 2021;3:321.

29. Hasanah YIF, Harahap Y, Suryadi H. Development and validation method of cyclophosphamide and 4-hydroxy cyclophosphamide with 4-hydroxy cyclophosphamide- $\mathrm{D}_{4}$ as internal standard in dried blood spots using UPLC-MS/MS. Int J Appl Pharm 2021;13:148-52.

30. Naveen VMK, Veeraswami B, Srinivasa Rao G. High response bio analytical validation approach of nadolol and bendroflumethiazide by LC-MS/MS on rat plasma. Int J Res Pharma Sci 2020;11:2272-9.

31. Gowri Kusuma Kumari, Rambabu Kantipudi. Bioanalytical method development and validation for avapritinib in rat plasma by LC-MS/MS. J Pharm Sci Res 2021;13:134-7.

32. Hemanth Kumar AK, Sudha V, Vijayakumar A, Padmapriyadarsini C. Simultaneous method for the estimation of bidaquiline and delamanid in human plasma using high-performance liquid chromatography. Int J Pharm Pharm Sci 2021;13:36-40.

33. Siva Madhu Chaitanya, Srinath Nissankararao, Satya Lakshmi Gandham. A sort of validated bioanalytical method developed for the estimation of etoposide and cisplatin in rat plasma by using two different advanced liquid chromatographic techniques like HPLC and UPLC and its application in bioequivalence studies. Int J Res Pharma Sci 2021;12:708-17. 